Document downloaded from:

http://hdl.handle.net/10251/120637

This paper must be cited as:

Parra-Boronat, L.; Lloret Mauri, G.; Lloret, J.; Rodilla, M. (2018). Physical Sensors for Precision Aquaculture: A Review. IEEE Sensors Journal. 18(10):3915-3923. https://doi.org/10.1109/JSEN.2018.2817158

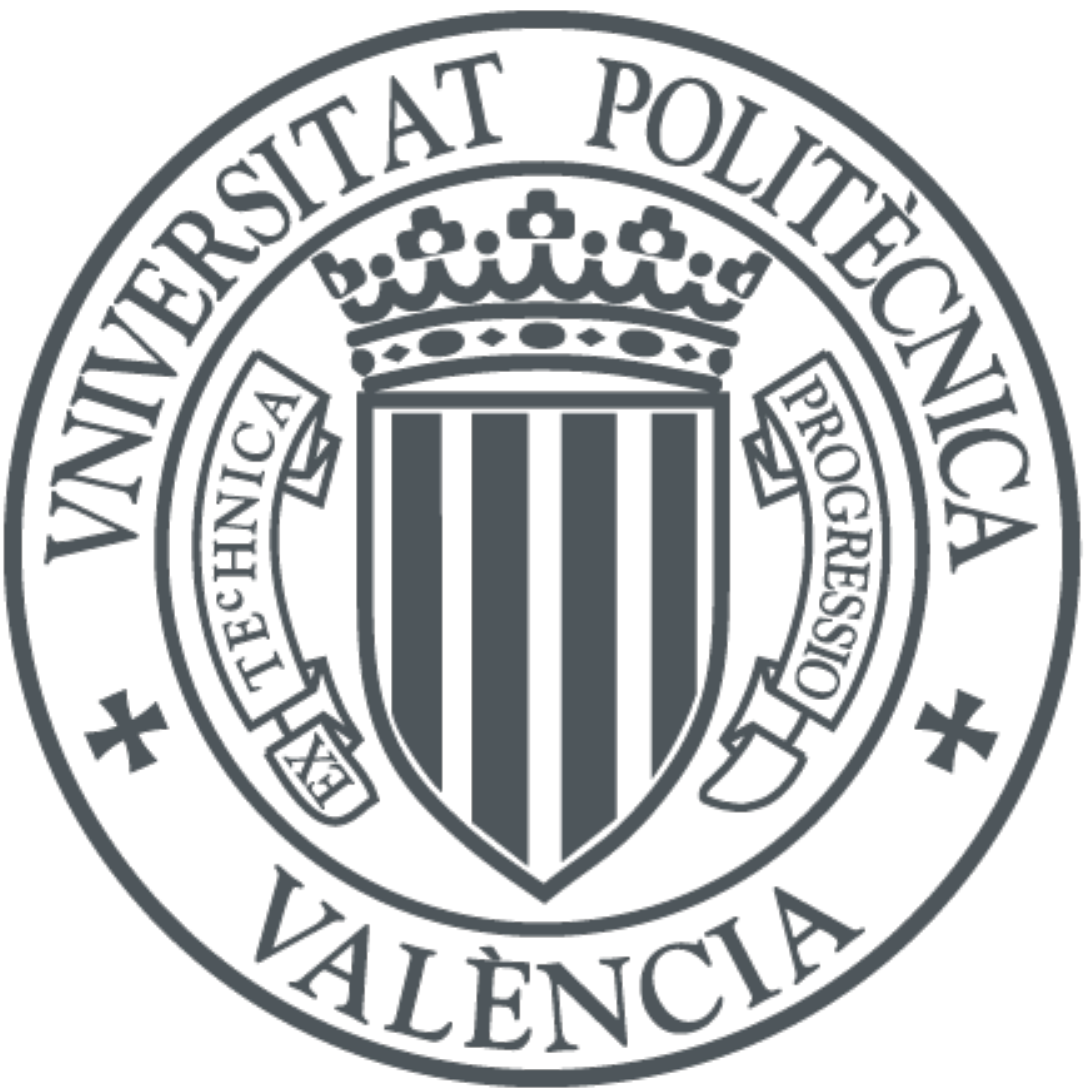

The final publication is available at

http://doi.org/10.1109/JSEN.2018.2817158

Copyright Institute of Electrical and Electronics Engineers

Additional Information

(c) 2018 IEEE. Personal use of this material is permitted. Permission from IEEE must be obtained for all other users, including reprinting/ republishing this 


\title{
Physical sensors for precision aquaculture: A Review
}

\author{
Lorena Parra ${ }^{1}$, Gines Lloret ${ }^{2}$, Jaime Lloret $^{1}$, Miguel Rodilla ${ }^{1}$ \\ ${ }^{1}$ Instituto de Investigación para la Gestión Integrada de zonas Costeras, Universitat Politecnica de \\ Valencia. C/ Paranimf, 146730 Grau de Gandia, Valencia, Spain \\ ${ }^{2}$ Fishing-Maritime Polytechnic Institute of the Mediterranean. Alicante, Spain. \\ Email: loparbo@doctor.upv.es, lloret_gin@gva.es, jlloret@dcom.upv.es,mrodilla@hma.upv.es
}

\begin{abstract}
Aquaculture is presented as a sustainable method to provide fish, although in reality, it is far from being sustainable. Its negative impacts on the environment can be prevented and corrected by the use of sensors, developing precision aquaculture. Sensors are widely used in terrestrial applications, but in underwater environments, their use is constrained by a variety of issues. The aim of this paper is to describe the state-of-art of the underwater sensors for water quality monitoring. First, the requirements and challenges of underwater sensors for aquaculture monitoring are discussed in detail. The main challenges are the need of a waterproof isolation or the need to avoid corrosion and biofouling, among others. Second, there are some advantages compared with terrestrial applications, such as no need of minimized systems or the fact that such systems only require low accuracy. Subsequently, we evaluated the different options available to sense each variable, related to the needs of the aquaculture sensors. For temperature monitoring, thermistors, thermocouples or RTC seem to offer similar advantages. In contrast, for dissolved oxygen monitoring, the optical method seems to be the best option. For turbidity, optical methods are the most employed ones, while for conductivity measurements, the inductive coils are a promising option.
\end{abstract}

Index Terms - Precision aquaculture, physical sensors, underwater sensors, water quality monitoring.

\section{INTRODUCTION}

Aquaculture products are presented as a sustainable alternative to the consumption of wild fish. However, nowadays, aquaculture systems are far from being sustainable. Habitat destruction, the need of wild fish for feed production and water pollution are some of these environmental impacts of aquaculture [1]. While in agriculture or farming, different technologies are being used to diminish those impacts, this is not the case for aquaculture. The main issue in applying these technologies to precision aquaculture is the different environment where the underwater wireless sensor networks (UWSN) and the remotely operated underwater vehicle (ROV) would have to be deployed. On the one hand, wireless communication between underwater devices is complex [2]. On the other hand, the need of a waterproof isolation for the sensors to ensure long-term monitoring hinders the manufacturing of underwater sensors.

The WSN and UWSN are composed by the sensing module, the central processing unit, the transceiver module and the battery unit [3]. The sensing modules must be adapted to the underwater environment [4]. The best option for sensing modules is physical sensors [5], which require low maintenance. In particular, they do not need continuous calibration or partial replacement over. In this context, the objective of this paper is to summarize the different available physical sensors for water quality monitoring to promote the use of physical sensor for precision aquaculture. The aim of this paper is to sum up the techniques and technologies available for water quality monitoring focusing on aquaculture environments and discuss its suitability for long-term monitoring of fish farms. Sensors proposed in papers and patents are included. In addition, we discuss the challenges of using physical sensors and UWSN. In terms of the sensors, we focus on the challenges related to the reduction of costs and long-term operations. The contributions of this paper are the following ones: (i) summarize the current technologies for monitoring temperature, dissolved oxygen, salinity and turbidity. (ii) Analyze the most employed technologies in commercial devices. (iii) Evaluate the current state and future challenges in aquaculture monitoring.

The rest of the paper is structured as follows: Section 2 presents the requirements of sensors suitable for aquaculture monitoring. The currently used sensors for temperature monitoring are shown in Section 3. Section 4 presents the different options for salinity sensing. Sensors for dissolved oxygen monitoring are described in Section 5. Section 6 details the different methods for turbidity sensing. The conclusions and future challenges are presented in Section 7. The conclusions and future work is shown in Section 8 . 


\section{2. REQUIREMENTS OF AQUACULTURE SENSORS}

In this section, the requirements and challenges for the sensors that will be used for precision aquaculture are shown. Although WSN are widely used in terrestrial applications, their use in the marine environment is limited. This underuse is caused by the special water attributes, the high cost of underwater sensors and failures due to the harsh environment. Battery issues and the difficulties of energy harvesting, telecommunication problems and sparse deployment are the challenges for the UWSN. To ensure suitability for aquaculture facilities, these sensors have to fulfil the following requirements. There are a paper which has already described the challenges for UWSN [6]. However, applying UWSN for aquaculture has some peculiarities which are addressed below.

First, the sensors have to be able to sense data over longer periods without having to be cleaned, maintained or replaced. The sensors in the fish farm will be deployed at different points. If sensors require attention, it would be necessary to allocate divers for maintenance tasks. The sensors may be placed in hard to reach places. Therefore, a sensor that needs daily calibration or weekly cleaning would not be suitable for long-term monitoring, which renders chemical sensors, as they require periodical calibration, unsuitable. The sensors that employ chemical compounds must be calibrated periodically. Moreover, the reagents must be refilled or changed. Sensors with membranes or electrolytes should also be avoided.

Second, the sensor nodes have limited battery power and the signal transmission consumes a great percentage of it. It is therefore important that the sensors have low energy demands to ensure long-term monitoring. If different options are available to measure the same parameters, it is important to select the option with low energy consumption. Periodical battery changes should be avoided for the same reason as explained above for cleaning or maintenance. Reducing energy consumption is essential, also in terms of communication, such as using energy-efficient protocols.

Third, seawater is a harsh environment. Salinity can cause corrosion and the currents can move the sensors and cause collisions. It is therefore important that the sensors are robust and have a protective layer. To prevent corrosion, the layer and any sensing part that will be in contact with the water must not contain any metallic materials. Therefore, the use of plastics and methacrylate is recommended [7, 8]. Waterproof insulation must be ensured. Depending on the depth, different options can be used, from simple waterproof silicone to special O-rings. The use of deflectors to ensure the orientation of the sensor with the changing currents of after collisions has to be considered.

Fourth, it should be noted that the sea is full of organisms which can alter the sensors. In the open sea, the available surface for living beings is limited. Every object that remains in the water will be subjected to biofouling. Many organisms will colonise every submerged surface, resulting in alterations in the buoyancy, the shape and the size of the sensor package. Microorganisms can alter the sensor surface and change the transparency and colour. Dead plankton can be deposited; hence, the potential light path must be properly designed. Several sensors are based on optical effects and need a light path. Those transparent sections should be placed in orientation to avoid deposition and biofouling. Photosynthetic organisms can generate oxygen bubbles that modify the light beam in optic sensors.

Macroinvertebrates will tend to use the nooks and crannies of the devices as hiding places, which might cause obstruction of the water current. In this case, the data may not represent the value of the surrounding water. If the sensors must be placed in a nook, is recommendable to add a grating to prevent macroinvertebrates from entering. The material of the grating must withstand biofouling and corrosion.

Fish can hit or bite the packages and therefore, fragile and soft parts should be covered. Fish such as Sparus aurata usually present biting behaviour in fish farms, related to the stress. This is also the case for Pomatomus saltatrix, a common predator. Such behaviour has been related to net holes $[9,10]$. To avoid damage caused by fish bites, the recommendation is to use packages with a spherical shape and with a diameter larger than the mouth of the fish. Thus, if spherical shapes are used there will be no points that stand out or edges in the package where the fish can bite.

The fifth consideration is focused on the effects that sensors may cause on the fauna. It is important to ensure that no harmful effects on fish are generated. For this reason, some sensing techniques must be avoided, in particular sensors that use (i) ultraviolet light (UV), (ii) acoustics beams that can be felt by fish and (iii) magnetic fields that may disturb their activity. The UV light can reduce growth rates in larvae and diminish its immune function [11]. The acoustic beams that produce high sound levels cause damages in the sound sensors cells, which can produce hearing loss [12]. Moreover, there are fish species that are magneto-sensitive [13].

It is important to ensure that the sensors do not alter fish swimming and feeding activities. Moreover, we need to ensure that sensors do not attract surrounding fauna, which can modify fish behaviour and produce stress. It is therefore crucial to test the potential harmful effects of the sensors.

Another problem of UWSN is the location of the sensor itself [14]. In sensors, such as current meters, the ability of the sensor to move and get oriented is needed. In this case, deflectors can be used to orient the sensor with the current. On the other hand, there are sensors that need to be in a fixed position with a specific orientation, avoiding any movement. Therefore, it might be necessary to include an anchor system. Although these systems can be added after the creation of the sensor, it is important to consider whether there is a need to have a fixed location. Devices with moving parts should be avoided, as such parts are susceptible to clogging.

Finally, sensors suitable for aquaculture and, generally, for marine monitoring, are relatively expensive. The costs of fabrication, deployment and recovery are significantly higher than those for terrestrial applications. In terrestrial applications, generally, the sensors are spread in the horizontal plane, while in marine monitoring; they are spread in the horizontal and the vertical planes, requiring the use of more sensors. It should be expected that a percentage of the total placed sensors are lost as a result of e.g. shock rupture or taken by the flow, which makes replacement from time to time necessary.

In summary, underwater sensors must be low maintenance, low cost, low battery consuming, robust, 
waterproof, non-metallic, withstand biofouling and have no effects on organisms. If possible, optical sensors should be avoided. It is important to study the threshold values of the hearing ability of fishes and the effects of magnetic fields.

On the other hand, there are advantages compared with applications that involve the people, mainly the fact that high accuracy is not important. While for those applications, high accuracy is needed, in aquaculture, the level of required accuracy is lower. Assuming that the sensors will be used for water monitoring to determine fish needs, a change of $0.01{ }^{\circ} \mathrm{C}$ or 0.01 PSU will not affect the fish. It is, however, important to study in detail the minimum variation of each parameters that affect fish.

Another advantage is that no minimised systems are needed. In applications, such as in e-health, small sensors are important to minimise potential discomforts, but this is not the case for aquaculture. The use of large sensors is even recommended, as small ones are easily lost and can be eaten.

\section{TEMPERATURE}

This section discusses the existing temperature sensors. Water temperature is mainly a factor of solar radiation and shows spatial and temporal variation. Annual cyclical changes are necessary for the correct sexual development and reproduction of fish [15]. For aquaculture, water temperature is the most important water parameter because it is highly correlated to fish performance. The effect of temperature has been studied $[16,17]$. In marine facilities, the changes in water temperature are related to annual cycles, meteorological conditions, changes in currents and climatic change. In the inland facilities with open water circuits, the changes can be higher than in marine facilities.

The following techniques are used for temperature sensing, which mainly fall into the two categories electric devices and non-electric devices. Electric devices need to be in contact with the sensed object, and the thermocouples are based on the Seebeck effect. They are composed of two connected metal conductors, usually made of copper, nickel, iron, platinum, rhodium and its alloys. Thermocouples are inexpensive, small and highly robust [18]. Although, they present low accuracy. They are used for water temperature monitoring [19].

The resistance of conductor materials (such as copper, gold, nickel, platinum or silver, among others) changes with the temperature. The resistance temperature device (RTD) has a higher accuracy than thermocouples, and the sensing range depends on the used material [18], i.e. from -100 to $100^{\circ} \mathrm{C}$ for copper. Two RTDs are available on the market; RTDs with higher accuracy made of platinum and RTDs known as thermistors. The platinum resistance thermometers (PRT) have a platinum coil wired over a glass made of quartz or mica. The PTR is mainly used to measure the water temperature of air conditioner systems. There is a linear relation between resistance and temperature. The thermistors are characterized by less accuracy, with a positive or a negative relation between resistance and temperature. They are known as negative temperature coefficient (NTC) or positive temperature coefficient (PTC). The NTC is commonly used for water temperature sensing [20] and water heating systems [21]. The PTC is used for water temperature monitoring [22].

Semiconductors, such as transistors or diodes, can also be used for temperature sensing. They are useful for sensing temperatures between -55 and $150^{\circ} \mathrm{C}$, with an accuracy higher than $1^{\circ} \mathrm{C}$. Their operation is based on the $\mathrm{p}-\mathrm{n}$ junction and the temperature dependence of the forward voltage drop. Diode thermometers are widely used because the relation between temperature and voltage drop is almost linear. Two of the most used semiconductors are $\mathrm{Si}$ and GaAsSi diodes are cheaper, GaAs diodes have a higher output. They are used for water temperature sensing as it was done in [23].

Another option for temperature sensing is the use of a capacitance thermometer. There are materials, such as strontium titanate, that their electric permittivity changes with the temperatures. They are used for low temperatures or high magnetic fields, but are not suitable for water temperature sensing. Less common sensing methods are the noise thermometry or the use of quartz thermometers. Noise thermometry is based on the thermal fluctuation of conductor materials and used for ultra-low temperatures in the millikelvin range [24]. Quartz thermometers are based on the vibration frequency of piezoelectric materials and they are mainly used for cryogenic measurements [25].

In contrast, non-electronic devices make use of the thermal expansion of materials with temperature. It is possible to distinguish the gas, the liquid-in-glass thermometers and the thermal expansion of solids. However, it is difficult to use this principle to create a sensor. In recent years, chemical compounds that change its colorations under different temperatures have been discovered. These chemical compounds are, however, not suitable for aquaculture. They must be in contact with the sensed object. Moreover, the degradation and the price of these materials render them unsuitable for our purpose.

Sensing techniques that do not require contact with the sensed medium are based on changes in electromagnetic radiations of an object at different temperatures. Infrared thermography can be used from 50 to $6,000 \mathrm{~K}$. Many materials can be used to detect IR emissions. Nevertheless, it is required that the sensor package has an optical window between the sensed element and the IR detector. As discussed above, optical solutions should be avoided when other options are available. Methods based on the measurement of the electromagnetic spectrum are available, but they are only suitable for higher temperatures. Finally, acoustic thermography is available to measure the temperature. The speed of sound in water depends on the temperature. Acoustic thermography can be used for detecting changes in deep-ocean temperature [26]. Its use has been described for deep oceans where the rest of the methods are not suitable.

The best option for temperature monitoring in water is the use of electronic devices, especially the RTD or the thermistor in terms of its high working range, adequate accuracy, and low price. Those sensors need to be in contact with the sensed medium, the water. Although our requirements include the need to avoid contact between the sensor and the water, they 
are the best option. There is a possibility to use a heat conductor package for the electric device.

\section{SALINITY}

Salinity in water is related to the presence of different ions. It is also known as electric conductivity (EC) and usually expressed in Siemens per meter $(\mathrm{S} / \mathrm{m})$, practical units of salinity (PSU) or $\mathrm{mg} / \mathrm{l}$. For aquaculture, EC is a critical parameter, and changes in salinity result in alterations of fish growth and survival [27, 28]. In marine facilities, water stratification, atmospheric changes and water currents can modify the salinity. They will need to control the salinity at different points in the horizontal and the vertical planes. In inland facilities, it is easier to monitor water EC in input pipes.

Water density, light refraction and electrical conductivity are the three physical parameters related to salinity [29]. The measuring of water density using a precise vibrating flow densimeter was widely used in the 1970s and 1980s in oceanographic studies. However, techniques based on light refraction or on EC, have become more practical over time and currently. No salinity sensors based on a precise vibrating flow densimeter can be found. The optical methods are based on the correlation between the refraction angle of an incident beam of light and the water salinity. When a light beam travels from reference water to sample water, the light has a refraction effect. Recording the point where the beam impacts, it is possible to know the salinity of the water sample. Based on this effect, the following sensor proposals have been developed[30-33], which distinguishing salinities from 0 to 50 PSU. Their range of measurements meets the requirements of salinity sensors for aquaculture. However, in the underwater environment, this system is not the most appropriate because it needs to keep clean the crystal surface.

There are two options to measure EC, the conductive and the inductive method, of which the conductive method is the most used one and based on the water resistivity. Two or more electrodes are used to calculate the conductivity. The conductance, $G$, is the reciprocal of the electrical resistance, $R$, as shows (Eq. 1). While the conductivity, $\sigma$, depends on the resistance and on the cell constant, $K c$, it has to be calculated for each design (Eq. 2). The $K c$ depends on the length of the electrode, $l$, and the area of the electrode, $A$ (Eq. 3.). Based on this theory, many designs appear. The simplest design is based on two electrodes [34]; however, it can cause water polarisation. For this reason, the authors have used more electrodes, and the design using four electrodes seems to be most common [35, 36]. Moreover, there are designs that use six electrodes [37]. Based on the electrode design, a small cell with a microfluidic channel and microelectrodes $[38,40]$ have been created. However, the main issue with this methodology, in the case of aquaculture monitoring, is the requirement that the electrodes stay in contact with the water, which can cause corrosion, biofouling and sedimentation, thereby altering the $K c$. They would require continuous cleaning and are not suitable.

$$
G=\frac{1}{R}
$$

$$
\begin{gathered}
\sigma=K c \times G \\
K c=\frac{l}{A}
\end{gathered}
$$

The inductive method is based on the use of two coils. The first coil is powered by an alternating current and generates a magnetic field. The intensity of the magnetic field is modified by the medium. In the secondary coil, the magnetic field induces an electric field that is correlated to the water salinity. As in the conductive method, many designs appear. The simplest one is formed by two one-turn coils [41]. The use of two toroidal coils was the most studied approach and is presented in the following publications [42, 44]. Designs formed by different combinations also appear in the literature $[45,46]$, but this methodology is less used. However, it presents advantages, mainly the possibility to isolate the sensing element, the coils, from the water.

Then, considering the cheap price, the highly accurate and that the measurement range fits with the requirements of aquaculture facilities, the inductive methodology is the best option to measure EC is the best option for salinity monitoring in fish farms. The devices can be isolated from the environment and at the used frequencies, no harmful effects on fish have been detected.

\section{DisSOLVED OXYGEN}

Dissolved oxygen is a measure of the concentration of oxygen in the water. For aquaculture, dissolved oxygen measurement is crucial. For adequate fish development, a minimum oxygen concentration is required, depending on the fish species. The negative effects of hypoxia on fish growth have been widely demonstrated, e.g. for Oreochromis niloticus [47] or for Oncorhynchus mykiss [48]. The concentration of oxygen in the water is a result of the equilibrium with the oxygen in the atmosphere [49]. The reduction of dissolved oxygen is caused by the presence of organisms (respiration and decomposition of organic matter by bacteria) and by some chemical reactions. The increase of oxygen concentrations is caused by photosynthesis. In marine facilities, a reduction of oxygen concentration under normal conditions is not common. However, some situation, such as an algae bloom, can produce a high oxygen demand during the night. In inland facilities, adverse situations can cause a reduction of oxygen concentrations in shallow waters. There are situations that may require the water to be kept in the tanks during long periods, resulting in low dissolved oxygen levels.

There are two main techniques to measure dissolved oxygen. The reference method is the Winkler test, which is based on a titration [50]. It is a complex method that requires the addition of reagents and cannot be used in a sensor. Nevertheless, it can be used for the sensor calibration. There are two groups of developed sensors: electrochemical and optical sensors. Electrochemical sensors are similar to the Clark electrode [51], which is an amperometric sensor based on the electrochemical cell. It is formed by a cathodic working electrode made of platinum, embedded in a cylindrical insulator and a ring-shaped silver anode. The used electrolyte is $\mathrm{KCl}$. An oxygen-permeable membrane is employed in the following designs (see [52, 54]) and use thick film technology. 
Other designs [55] used a modified glassy carbon electrode; the design proposed by $\mathrm{Xu}$ et al. [56] is an example of a lowcost design. The main disadvantages of the sensors that present a permeable membrane are the dependence of the oxygen diffusivity on the pressure [57]. Moreover, they need to be cleaned periodically. There are, however, designs without membranes [57], which serve as prototypes for laboratory use, but are not suitable for in situ measurements. A needle-type dissolved oxygen microelectrode array sensor [58] and a microelectrode sensor designed by Sosna et al. [59] are designed as a miniaturized system. Nevertheless, those designs need continuous maintenance. The electrodes have to be in contact with the water and sedimentation, biofouling or air bubbles can disturb the measurement. Optical sensors are based on collisional quenching by molecular oxygen of a chemical compounds embedded in a support matrix [60]. Two main groups of chemical complexes are used, based on platinum (II) [61, 62] or ruthenium (II) [63, 67].

From the current options, the optical oxygen sensors are the best option for in-situ monitoring considering that the other option, the Clack electrode sensors need to be cleaned periodically. Nevertheless, the chemical compounds employed in the optical sensors usually degrade over time and need replacement. Moreover, they are relatively expensive, which impedes their use in aquaculture facilities. Furthermore, biofouling and sedimentation can obstruct the contact between water and the sensing element. For this reason, it will be necessary to search for a region of the light spectrum in the UV light that allows measuring the absorbance of light and correlates it with the dissolved oxygen.

\section{TURBIDITY}

Turbidity is a measure of the transparency of water, and reduced turbidity is related to the presence of suspended sediments (SS). For aquaculture, turbidity increase can cause problems in the fish, the effect of turbidity on fish is complex. In species, such as Erimonax monachus, increased turbidity causes a reduction in growth [68]. In other species, such as Stizostedion vitreum, maximum growth is reached at highest turbidity [69]. Turbidity can be caused by inert particles such as sedimentary turbidity. Moreover, it can be caused by living particles, such as plankton. In marine facilities, abrupt changes in turbidity are not usual and generally related to high phytoplankton blooms or some adverse methodological conditions. Inland facilities can be affected by sedimentary of planktonic turbidity. In this case, the use of filters can reduce its effects. However, it is necessary to monitor turbidity to take the needed steps.

Turbidity can be measured using different techniques. There are techniques, such as the use of a Secchi disk, gravimetric methodology or the Imhoff cone, which are not suitable for automatic techniques. Techniques based on light effects are related to the Beer-Lambert law (Eq. 4), which quantifies the transmitted light, It, as a function of the light intensity of a source, $I o$, the absorption coefficient per unit length, $a$, the turbidity, $t$ and the length of the light pass, $l$, [71].

$$
I t=I o \times e^{-(a \times t) l}
$$

Based on the Eq. 3, there are different methodologies to measure water turbidity. Nephelometers are based on the measurement of the scattered light. The light sensing component is usually positioned at $90^{\circ}$, or a lower angle, from the light source. This method is usually employed to measure samples with low turbidity values [71]. There are few proposals based on this methodology (e.g. [72]), where a diode is used as a light emitter and a photodiode as a light detector. Another example can be found in Lambrou et al. [71], with a sensing range from 0 to 120 NTU.

The second methodology, using turbidimeters, is focused on the absorption of the light. The undissolved particles cause light scattering and light absorption. This methodology is proposed for samples with high turbidity values [71]. Some examples of prototypes based on this methodology can be found in the literature. One sensor uses a diode with the peak wavelength at $950 \mathrm{~nm}$ and an IR photodiode with a sensing range from 0 to 1,000 NTU [73]. Giuffre et al. [74] presented a similar prototype and Biard [75] improved the existing prototype. In this case, the author added a second photodiode next to the light emitted to evaluate the light intensity before passing through the sample. Similarly, [76] placed the detector at $360^{\circ}$ from the emitter and used a lent to reflect the light. In the ratio turbidimeter, two light detectors are used, placed at $180^{\circ}$ and $90^{\circ}$. This methodology is recommended for water with high turbidity levels and coloured samples. Sensing ranges goes from 0 to $120 \mathrm{NTU}$ [71]. An improvement was presented by in [70, 77], who proposed to use an extra photodetector, resulting in a system with one emitter and three detectors at $90^{\circ}, 180^{\circ}$ and $270^{\circ}$. With this enhancement, the sensing range reaches 1,000 NTU.

There is another physical principle to measure turbidity. The presence of SS produces alterations in an acoustic beam. The use of high-frequency acoustic beams to measure turbidity presents better results because it is independent of the particle size. Clifford et al. [78] demonstrated that the particle size affects the readings. For this reason, the use of acoustic doppler velocimetry (ADV) seems a better option for monitoring water turbidity. There are different options to relate the SS with the sound alterations. The first one is to use a probe for measuring the acoustic backscattering intensity (BSI). The BSI technique is based on the sonar equation for sound scattering from small particles or SS. Several authors have studied the relation between BSI and turbidity [79-82]. Besides, the acoustic beam amplitude can be used to estimate turbidity [83]. Chanson et al. [84] presented both methodologies with good correlations. Finally, the sound noise ratio signal indicates that the scattered sound pulses are correlated to turbidity [85].

After analysing all current options for turbidity measurement, two main groups could be distinguished. First, sensors based on an optical beam, where absorption, refraction or both are measured. Another option is the use of an acoustic beam. In this case, both options present their own problems. Optical methods should be avoided. However, acoustic methods employ higher energy than optical methods. Moreover, acoustic sensors are usually more expensive than optical sensors. Therefore, in term of the energy consumption and price the best option $\mathrm{i}$ to use the sensor based on optical 
absorbed and/or scattered light; moreover, their accuracy and working rate fits with the need on aquaculture facilities.

\section{DISCUSSION AND FUTURE CHALLENGES}

This paper presents a review of the current options for water quality monitoring. The challenges for water quality monitoring in the fish farm environment are shown and the required characteristics of the employed sensors for long-term monitoring are detailed. Although the use of sensors is common for terrestrial applications, such as monitoring agricultural and livestock processes, its use in underwater environments is reissued. The main reasons are the differences between air and water environments. The characteristics of the underwater and, especially, saline environments can cause alterations in the sensor. Because of this, many measures must be taken to protect the sensors from the harsh environment. Waterproof packages or of the avoidance of materials that corrode are posible solutions. Furthermore, there are certain restrictions to access the sensors. Therefore, in long-term monitoring, it is important to minimise replacement. The need for battery replacement and cleaning must be considerably reduced. Hence, it is extremely important to reduce the energy consumption of the sensor, which stresses the need for sensing methods with low energy requirements. Moreover, those sensors must have low maintenance needs. In general terms, optic sensors must be avoided because they need to be cleaned frequently. However, if no other option is feasible, a proper orientation can be chosen to avoid sedimentation and to reduce maintenance. The effect of change the orientations must be studied in order to find the best option to reduce the accumulation of sediment. In general it is preferred vertical orientations than horizontal ones. To avoid damage by fish, special shapes and sizes can be selected. The use of spherical shapes in the sensors inside the cage will ensure that the sensors will not cause any damage to the fish if they collide with or bite the sensor. Sensors need to be available at low costs if we pretend to impulse the use of sensors for precision aquaculture.

For the review of different methodologies for temperature, salinity, dissolved oxygen and turbidity measures, papers and patents were analysed in order to prepare a selection of the most suitable options for water quality monitoring. According to the challenges and needs described above, the best options to sense each parameter were selected. For temperature monitoring, the best option is to use electronic devices such as RTD or thermistors. They are cheap, easy to isolate and sufficiently adequate. Usually, they consume low amounts of energy and can be easily powered with a normal sensor node such as Flyport, Waspmote or Arduino. The best option for salinity monitoring is the measurement of EC by the use of inductive methods. The coils used for these methods can be isolated from the water. Depending on the coil, the sensors consume low amounts of energy. Furthermore, they are cheap and can be powered with a regular node. For turbidity measurement, optical sensors are most suitable, either scattering or backscattering methods. They are cheaper than the use of acoustic beams and require less amounts of energy. The use of a light source and detector can be easily implemented in a node of a WSN. Although the use of a light beam should be avoided, this is the best option in this case. For dissolved oxygen monitoring, there are two groups of sensors, ones based on collisional quenching and ones based on the Clark electrode. Unfortunately, both of them need regular maintenance and replacement. However, there are no other options at this moment. The most appropriate option for long-term monitoring is the use of optical sensors. The main advantage of this sensor is its robustness. Nevertheless, it is important to remark that optical sensors for dissolved oxygen monitoring are usually more expensive.

Next, data about the real implementations based on the commercial available devices. First, the different technologies employed in the available probes are shown. The following factories including In-Situ Inc, SEBA, Hanna, YSI, Eureka water probes, Aquatec Group, OTT, Saiv A/S, INW TempHion, Crison, PCE Instruments, Zebra-Tech or Hach were studied to elaborate Figures 1 to 4 . Up to 100 sensors for 13 factories were analyzed to elaborate Figures 1 to 4 . In Figures 1 to 4 , it is possible to see the number of sensors in each category and the percentage of each category. The companies offer the following solutions for temperature monitoring, see Figure 1. The RTDs and thermistors seem to be the most common solutions. Our analyses considering the options described in Section 3 conclude that the best option was to use RTD or the thermistors for water quality monitoring. The commercial devices use the same option pointed out previously. Figure 2 shows the currently used commercial sensors, of which the majority are based on electrodes. Nevertheless, an inductive sensor can be obtained from Saiv A/S. In section 4 we conclude that the best option was to use the inductive sensors. Most of the commercial devices are not yet including this technology. We can expect that the inductive technology will be used in the future for water quality monitoring. Figure 3 shows the currently used sensors to measure dissolved oxygen. Most of them are optical sensors, while only three are based on the Clark cell. In Section 5 we conclude that the best option was the optic sensors and the commercial devices are mainly using the optic methods. However, it is necessary to point that the optic methods require maintenance due to the membranes. Figure 4 shows the currently used commercial sensors based on light effects. No company offers solutions based on acoustic effects. Our recommendation in Section 6 was to use the optical sensors. All the available options is the market goes in this direction. Finally, the information about few devices capable to monitor the listed parameters in this paper is shown in Table 1 [86-90]. It is possible to see that the enterprises mentioned in Table 1 are producing probes that can be employed in aquaculture facilities. As Table 1 includes only the probes founded that are able to measure all the parameters selected in this paper, many probes from different factories are not included. The main disadvantage of the current available sensors is its price. From some sensors there is no information (NI) about the used technology. Water temperatures in marine waters range from 0 to $29.5^{\circ} \mathrm{C}$ [91], and all the presented sensors are suitable for temperature monitoring according to their operational range. Generally, marine water salinity 
ranges from 29 to $38 \mathrm{mg} / \mathrm{L}$ [92], all the sensors are able to cover this range of salinities. The average oxygen concentration in the water surface ranges from 4.6 in the tropics and $9.0 \mathrm{mg} / \mathrm{L}$ in the Artic [93], without any significant changes throughout the year. In aquaculture facilities, the oxygen concentration can diminish. All the included sensors in Table I present an operational range suitable for the range of dissolved oxygen at the sea surface. The range that present the turbidity sensors above are adequate for the expected levels in the fish farms.

In the future, the challenges in underwater sensing for aquaculture monitoring will be based on long-term monitoring. To address this goal, it will be necessary to encourage researchers to develop new physical methods for

TABLE I

COMMERCIALLY AVAILABLE SENSORS FOR MONITORING

\begin{tabular}{|c|c|c|c|c|c|c|c|c|c|}
\hline Factory & Tempe & $\begin{array}{l}\text { Rare } \\
\text { Range } \\
\left({ }^{\circ} \mathrm{C}\right) \\
\end{array}$ & Type & $\begin{array}{l}\text { ty } \\
\text { Range } \\
(\mathrm{mS} / \mathrm{cm})\end{array}$ & $\begin{array}{l}\text { Dissolve } \\
\text { Type }\end{array}$ & $\begin{array}{l}\text { oxygen } \\
\text { Range } \\
(\mathrm{mg} / \mathrm{l})\end{array}$ & Type & $\begin{array}{l}\text { rbidity } \\
\text { Range } \\
\text { (NTU) }\end{array}$ & Ref. \\
\hline In-Situ Inc & Thermistor & -5 to 50 & Electrodes & 0 to 350 & Optic & 0 to 50 & Optic & 0 to 4,000 & {$[86]$} \\
\hline In-Situ Inc & Thermistor & -5 to 50 & Electrodes & 5 to 112 & $\begin{array}{l}\text { Optic \& } \\
\text { Clark cell }\end{array}$ & $\begin{array}{l}0 \text { to } 50 \& \\
0 \text { to } 20\end{array}$ & Optic & 0 to 2,000 & [87] \\
\hline SEBA & NTC & -5 to 50 & 4 electrodes & 0 to 200 & N.I. & 0 to 25 & Optic & 0 to 1,000 & [88] \\
\hline SEBA & NTC & -5 to 50 & 4 electrodes & 0 to 200 & Optic & 0 to 40 & Optic & 0 to 1,000 & [89] \\
\hline Hanna & N.I. & -5 to 50 & N.I. & 0 to 200 & N.I. & 0 to 50 & Optic & 0 to 1,000 & [90] \\
\hline
\end{tabular}

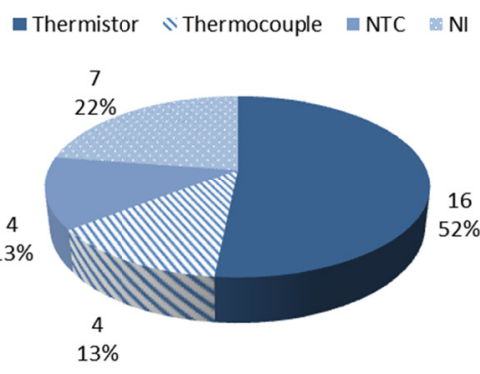

Figure 1. Employed technology on temperature sensors

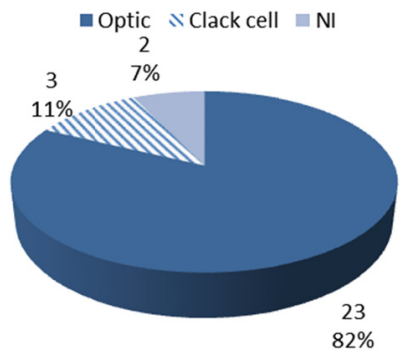

Figure 3. Employed technology on dissolved oxygen sensors

\section{CONCLUSIONS}

In this paper we set the requirements for the sensors to aquaculture monitoring. Then, we analyse the current technologies and compare them with the requirements. For parameters, such as salinity and temperature, the available sensors meet all the requirements for water quality monitoring in aquaculture facilities. However, for turbidity and dissolved oxygen, the current sensors do not fulfil the described needs. Find new sensing technologies for those parameters is an emerging and important field. Recently, the WSN has demonstrated several benefits for process monitoring.

Our future work will be focused on using the selected sensors to create a WSN for water quality monitoring in turbidity and dissolved oxygen monitoring. The reduction of biofouling is one of the major challenges in terms of reducing maintenance needs. The investigation of materials that withstand corrosion and biofouling processes is crucial. Moreover, the inclusion of energy harvesting techniques in underwater environments will facilitate long-term monitoring, without the need of battery replacement. The most important challenge is that the developed sensors have no negative effects on fish, which requires studies with live organisms. Further, the sensors should not cause any effects after short or chronic exposure, in fish swimming and feeding behaviour and feeding or changes in the immunological system.

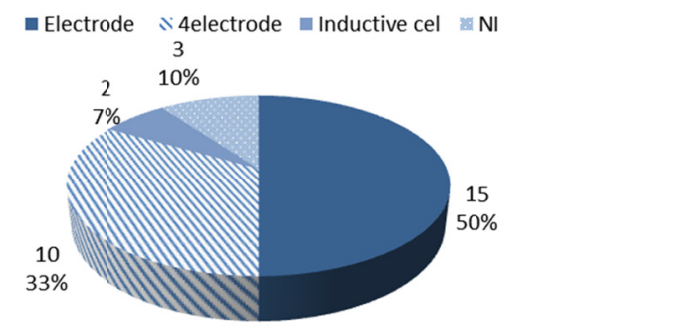

Figure 2. Employed technology on salinity sensors

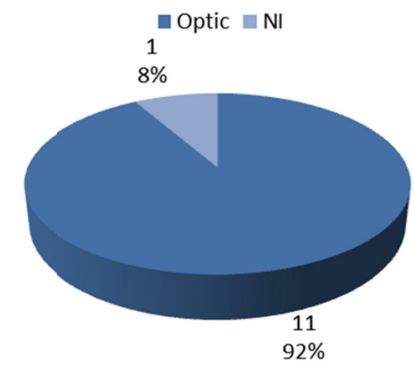

Figure 4. Employed technology on turbidity sensors

aquaculture facilities similar to the one presented in [94, 95]. We will also include data about feed consumption and implement artificial intelligence techniques to build an intelligent system for fish farm monitoring, with the overall aim to improve aquaculture efficiency.

\section{ACKNOWLEDGMENT}

This work has been partially supported by the pre-doctoral student grant "Ayudas para contratos predoctorales de Formación del Profesorado Universitario FPU (Convocatoria 2014)" with reference: FPU14/02953 by the "Ministerio de Educación, Cultura y Deporte". 


\section{REFERENCES}

[1] J. Primavera, Overcoming the impacts of aquaculture on the coastal zone. Ocean Coast Manage, 2006, v. 49, no 9, p. 531-545.

[2] S. Sendra, J. Lloret, J. M. Jimenez, L. Parra, Underwater acoustic modems. IEEE Sensors J., 2016, v.16, n.11, p. 4063-4071.

[3] S. Sendra, J. Lloret, M. García, J.F. Toledo, Power saving and energy optimization techniques for wireless sensor neworks, Journal of communications 6 (6), 439-459. 2011

[4] S. Sendra, L. Parra, J. Lloret, J. M. Jiménez, Oceanographic multisensor buoy based on low cost sensors for Posidonia meadows monitoring in Mediterranean Sea. J Sensors, 2015, vol. 2015.p 1-23. [5] J. Goldman, N. Ramanathan, R. Ambrose, D.A. Caron, D. Estrin, J.C. Fisher, R. Gilbert, M.H. Hansen, T.C. Harmon, J. Jay, W.J. Kaiser, G.S. Sukhatme, Y.C. Tai, Distributed sensing systems for water quality assessment and management: White Paper published and prepared by the Foresight and Governance Project at the Woodrow Wilson International Center for Scholars, 2007.

[6] M. Garcia, S. Sendra, M. Atenas, J. Lloret, Underwater wireless ad-hoc networks: A survey, Mobile ad hoc networks: Current status and future trends, 2011, p. 379-411.

[7] C.K. Harnett, S.M. Courtney, C.J. Kimmer, SALAMANDER: A distributed sensor system for aquatic environmental measurements. Int. Conf. on IEEE Instrumentation and Measurement Technology Conference, Victoria, British Columbia, Canada, May 12-15 2008.

[8] L. Parra, E. Karampelas, S. Sendra, J. Lloret, J.J. Rodrigues. Design and deployment of a smart system for data gathering in aquaculture tanks using wireless sensor networks. International Journal of Communication Systems, 2017, vol. 30, no 16, p. 1- 15.

[9] H. Moe, T. Dempster, L. M. Sunde, U. Winther, A. Fredheim, Technological solutions and operational measures to prevent escapes of Atlantic cod (Gadus morhua) from sea cages. Aquac Res, 2007, v. 38, n. 1, p. 91-99.

[10] P. Sanchez-Jerez, D. Fernandez-Jover, J. Bayle-Sempere, C. Valle, T. Dempster, F. Tuya, F. Juanes, Interactions between bluefish Pomatomus saltatrix (L.) and coastal sea-cage farms in the Mediterranean Sea. Aquaculture, 2008, v. 282, n. 1, p. 61-67.

[11] D.P. Häder E.W. Helbling, C.E. Williamsonc, R.C. Worrestd, Effects of UV radiation on aquatic ecosystems and interactions with limate change. Photochem. Photobiol. Sci.,2011, v.10,n.2, p.242-260. [12] A.N. Popper, J. Fewtrell, M.E. Smith, R.D. McCauley, Anthropogenic sound: effects on the behavior and physiology of fishes. Mar. Technol. Soc. J., 2003, v. 37, n. 4, p. 35-40.

[13] M.C. Öhman, P. Sigray, H. Westerberg, Offshore windmills and the effects of electromagnetic fields on fish. AMBIO: A journal of the Human Environment, 2007, v. 36, n 8, p. 630-633.

[14] G. Han, C. Zhang, L. Shu, J.J.P.C. Rodrigues, Impacts of deployment strategies on localization performance in underwater acoustic sensor networks. IEEE Trans. Ind. Electron., 2015, v. 62, n 3, p. 1725-1733.

[15] N. W. Pankhurst, H. R. King, Temperature and salmonid reproduction: implications for aquaculture. J Fish Biol, 2010, v. 76, n. 1 , p. 69-85.

[16] N. Wang, X. Xu, P. Kestemont, Effect of temperature and feeding frequency on growth performances, feed efficiency and body composition of pikeperch juveniles (Sander lucioperca). Aquaculture, 2009, v. 289, n. 1 , p. 70-73.

[17] M. S. Azaza, M. N. Dhraief, M. M. Kraiem, Effects of water temperature on growth and sex ratio of juvenile Nile tilapia Oreochromis niloticus (Linnaeus) reared in geothermal waters in southern Tunisia. J therm Biol, 2008, v. 33, n. 2, p. 98-105.

[18] P. R. N. Childs, J. R. Greenwood, C. A. Long, Review of temperature measurement. Rev Sci Instrum, 2000, v. 71, n. 8, p. 2959-2978.

[19] K. Dickson, Tunas as small as $207 \mathrm{~mm}$ fork length can elevate muscle temperatures significantly above ambient water temperature. J Exp Biol, 1994, v.190, n.1, p. 79-93.
[20] S. Rayne, G. Henderson, P. Gill, K. Forest, Riparian forest harvesting effects on maximum water temperatures in wetlandsourced headwater streams from the Nicola River Watershed, British Columbia, Canada. Water Resour Manag,2008, v.22, n.5, p. 565-578. [21] J. A. B. Vieira, A. M. Mota, Thermoelectric generator using water gas heater energy for battery charging. IEEE Control Applications, (CCA 2009) \& Intelligent Control, (ISIC 2009), St.Petersburg, Russia, 8-10 July, 2009.

[22] I. Chaput, Instant water heater with PTC plastic conductive electrodes. U.S. Patent No 7,327,951, 5 Feb. 2008.

[23] N. Emery, A. Caughley, N. Glasson, J. Meier, M. Nation, J., Tanchon, T. Trollier, A. Ravex, Co-axial pulse tube development. Cryocoolers, 2012, v. 17, n. 1, p. 135-141.

[24] C. P. Lusher, J. Li, V. A. Maidanov, M. E. Digby, H. Dyball, A. Casey, J Nyéki, V V Dmitriev, B P Cowan J Saunders, Current sensing noise thermometry using a low Tc DC SQUID preamplifier. Meas Sci Technol, 2001, v. 12, n. 1.

[25] L. G. Rubin, Cryogenic thermometry: a review of progress since 1982. Cryogenics, 1997 , v. 37, n. 7, p. 341-356.

[26] K. F. Woolfe, S. Lani, K. G. Sabra, W. A. Kuperman, Monitoring deep-ocean temperatures using acoustic ambient noise. Geophys Res Lett, 2015, v. 42, n. 8, p. 2878-2884.

[27] V. C. Rubio, F. J. SáncheztoVázquez, J. A. Madrid, Effects of salinity on food intake and macronutrient selection in European sea bass. Physiol Behav, 2005, v. 85, n. 3, p. 333-339.

[28] M. J. Resley, K. A. Webb, G. J. Holt, Growth and survival of juvenile cobia, Rachycentron canadum, at different salinities in a recirculating aquaculture system. Aquaculture, 2006, v. 253, n. 1, p. 398-407.

[29] O. Postolache, P. S. Girão, J. M. D. Pereira, Water quality monitoring and associated distributed measurement systems: An Overview. Water Quality Monitoring and Assessment. InTech, 2012. [30] Y. Zhao, X. Zhang, T. Zhao, B. Yuan, S. Zhang, Optical salinity sensor system based on fiber-optic array. IEEE Sensors J., 2009, v. 9 , n. 9 , p. 1148-1153.

[31] Y. Zhao, Y. Liao, Novel optical fiber sensor for simultaneous measurement of temperature and salinity. Sensor Actuat B-Chem, 2002, v.86, n.1, p. 63-67.

[32] O. Esteban, M. Cruz-Navarrete, A. González-Cano, E. Bernabeu, Measurement of the degree of salinity of water with a fiber-optic sensor. Applied optics, 1999, v. 38, n. 25, p. 5267-5271.

[33] Y. Zhao, B. Zhang, Y. Liao, Experimental research and analysis of salinity measurement based on optical techniques. Sensor Actuat B-Chem, 2003, v.92,n.3,p.331-336.

[34] S. H. Russ, V. Perepa, S. Leavesly, B. Webb, B. Novel lowtocost salinity sensor for embedded environmental monitoring. IEEE SoutheastCon 2010 (SoutheastCon), Concord, USA, 18-21 March, 2010.

[35] H. Ramos, L. Gurriana, O. Postolache, M. Pereira, P. Girão, P. Development and characterization of a conductivity cell for water quality monitoring. Third IEEE Int. Conf. on Systems, Signals \& Devices (SSD’2005), Sousse, Tunísia, 21-24 March, 2005.

[36] P. M. Ramos, J. D. Pereira, H. M. G. Ramos, A. L. Ribeiro, A four-terminal water-quality-monitoring conductivity sensor. IEEE Trans. Instrum. Meas, 2008, v. 57, n. 3, p. 577-583.

[37] N. L. Brown, N. L. New generation CTD system (conductivitytemperature-depth sensor). IEEE J Oceanic Eng, 1988, v. 13, n. 3, p. 129-134.

[38] W. Gong, M. Mowlem, M. Kraft, F. Morgan, F. Oceanographic sensor for in-situ temperature and conductivity monitoring. OCEANS 2008-MTS/IEEE Kobe Techno-Ocean, Kobe,Japan, 8-11April, 2008. [39] X. Huang, R. W. Pascal, K. Chamberlain, C. J. Banks, M. Mowlem, H. Morgan, A miniature, high precision conductivity and temperature sensor system for ocean monitoring. IEEE Sensors J, 2011, v. 11 , n. 12 , p. 3246-3252. 
[40] M. Kim, W. Choi, H. Lim, S. Yang, Integrated microfluidicbased sensor module for real-time measurement of temperature, conductivity, and salinity to monitor reverse osmosis. Desalination, 2013, v. 317, p. 166-174.

[41] R. L. Kleinberg, W. C. Chew, D. D. Griffin, Noncontacting electrical conductivity sensor for remote, hostile environments. IEEE Trans. Instrum. Meas., 1989, v. 38, n. 1, p. 22-26.

[42] T. T. Pham, T. Green, J. Chen, P. Truong, A. Vaidya, L. Bushnell, A salinity sensor system for estuary studies. IEEE OCEANS 2008, Quebec City, Canada, 15 - 18 Sept., 2008.

[43] R. T. Wood, A. Bannazadeh, N. Q. Nguyen, L. G. Bushnell, A salinity sensor for long-term data collection in estuary studies. IEEE OCEANS 2010 Seattle, USA, 20-23 Sept., 2010.

[44] L. Parra, V. Ortuño, S. Sendra, J. Lloret, Water Conductivity Measurements Based on Electromagnetic Fields. Int. Conf. on Computational Science and Engineering (CSE'13), Valencia, Spain, 6-8 of Aug. 2013.

[45] L. Parra, V. Ortuño, S. Sendra, J. Lloret, Low-cost conductivity sensor based on two coils. Int. Conf. on Computational Science and Engineering (CSE'13), Valencia, Spain, 6-8 Aug. 2013.

[46] L. Parra, S. Sendra, J. Lloret, J. J. P. C. Rodrigues, Low cost wireless sensor network for salinity monitoring in mangrove forests. Int. Conf. on IEEE SENSORS 2014, Valencia, Spain, 2-5 Nov. 2014. [47] A. Tran-Duy, J. W. Schrama, A. A. van Dam, J. A. Verreth, Effects of oxygen concentration and body weight on maximum feed intake, growth and hematological parameters of Nile tilapia, Oreochromis niloticus. Aquaculture, 2008, v. 275, n. 1, p. 152-162.

[48] C. S. Ciuhandu, E. D. Stevens, P. A. Wright, The effect of oxygen on the growth of Oncorhynchus mykiss embryos with and without a chorion. J. fish biol, 2005, v. 67, .6, p. 1544-1551.

[49] H. E. Garcia, L. I. Gordon, Oxygen solubility in seawater: Better fitting equations. Limnol Oceanogr, 1992, v. 37, n. 6, p. 1307-1312.

[50] L. W. Winkler, The determination of dissolved oxygen in water Berichte der Deutschen Chemischen Gesellschaft, v. 21, n.. 2, 1888, p. 2843-2854.

[51] L. C. Clark, R. Wolf. D. Granger, Z. Taylor, Continuous recording of blood oxygen tensions by polarography. J Appl Physiol, v. 6, n.. 3, 1953, 189-193.

[52] F. J. H. Mackereth, An improved galvanic cell for determination of oxygen concentrations in fluids. Journal of Scientific Instruments, v. 41, n. $1,1964,38$.

[53] W. Glasspool, J. Atkinson, A screen-printed amperometric dissolved oxygen sensor utilising an immobilised electrolyte gel and membrane. Sensor Actuat B-Chem, 1998, v. 48, n. 1, p. 308-317.

[54] R. Martínez-Máñez, J. Soto, J. Lizondo-Sabater, E. GarcíaBreijo, L. Gil, J. Ibáñez, I. Alcaina, S. Alvarez, New potentiomentric dissolved oxygen sensors in thick film technology. Sensor Actuat BChem,2004,v.101,n.3,p.295-301.

[55] R. D. C. S. Luz, F. S. Damos, A. A. Tanaka, L. T. Kubota, Dissolved oxygen sensor based on cobalt tetrasulphonated phthalocyanine immobilized in poly-1-lysine film onto glassy carbon electrode. Sensor Actuat B-Chem, 2006, v. 114, n. 2, p. 1019-1027.

[56] X. Xu, C. Liu, J. Jia, B. Liu, X. Yang, S. Dong, A simple and inexpensive method for fabrication of ultramicroelectrode array and its application for the detection of dissolved oxygen. Electroanal, 2008 ,v.20, n.7, p.797-802.

[57] M. Sosna, G. Denuault, R. W. Pascal, R. D. Prien, M. Mowlem, Development of a reliable microelectrode dissolved oxygen sensor. Sensor Actuat B-Chem, 2007, v. 123, n. 1, p. 344-351.

[58] J. H. Lee, T. S. Lim, Y. Seo, P. L. Bishop, I. Papautsky, Needletype dissolved oxygen microelectrode array sensors for in situ measurements. Sensor Actuat B-Chem, 2007, v.128, n. 1, p. 179-185. [59] M. Sosna, G. Denuault, R. W. Pascal, R. D. Prien, M. Mowlem, Field assessment of a new membrane-free microelectrode dissolved oxygen sensor for water column profiling. Limnol Oceanogr-Meth, 2008, v. 6, n. 4, p. 180-189.
[60] C. S. Chu, Y. L. Lo, Optical fiber dissolved oxygen sensor based on Pt (II) complex and core-shell silica nanoparticles incorporated with sol-gel matrix. Sensor Actuat B-Chem, 2010, v.151,n.1,p.83-89. [61] W. Trettnak, C. Kolle, F. Reininger, C. Dolezal, P. O'Leary, Miniaturized luminescence lifetime-based oxygen sensor instrumentation utilizing a phase modulation technique. Sensor Actuat B-Chem, 1996, v. 36, n. 1-3, p. 506-512

[62] T. S. Yeh, C. S. Chu, Y. L. Lo, Highly sensitive optical fiber oxygen sensor using Pt (II) complex embedded in sol-gel matrices. Sensor Actuat B-Chem, 2006, v. 119, n. 2, p. 701-707.

[63] W. Trettnak, C. Kolle, F. Reininger, C. Dolezal, P. O'Leary, R. A. Binot, Optical oxygen sensor instrumentation based on the detection of luminescence lifetime. Adv Space Res, 1998, v. 22, n. 10, p. $1465-1474$.

[64] C. McDonagh, C. Kolle, A. K. McEvoy, D. L. Dowling, A. A. Cafolla, S. J. Cullen, B. D. MacCraith, Phase fluorometric dissolved oxygen sensor. Sensor Actuat B-Chem, 2001, v. 74, n. 1, p. 124-130. [65] A. Sin, K. C. Chin, M. F. Jamil, Y. Kostov, G. Rao, M. L. Shuler, The design and fabrication of three-chamber microscale cell culture analog devices with integrated dissolved oxygen sensors. Biotechnol Progr, 2004, v. 20, n. 1, p. 338-345.

[66] P. A. S. Jorge, P. Caldas, C. C. Rosa, A. G. Oliva, J. L. Santos, Optical fiber probes for fluorescence based oxygen sensing. Sensor Actuat B-Chem, 2004, v. 103, n. 1, p. 290-299.

[67] R. C. Evans, P. Douglas, J. G. Williams, D. L. Rochester, A novel luminescence-based colorimetric oxygen sensor with a "traffic light" response. J Fluoresc, 2006, v. 16, n. 2, p. 201-206.

[68] A. B. Sutherland, J. L. Meyer, Effects of increased suspended sediment on growth rate and gill condition of two southern Appalachian minnows. Environ Biol Fish, 2007, v.80, n.4, p.389-403. [69] P. W. Rieger, R. C. Summerfelt, The influence of turbidity on larval walleye, Stizostedion vitreum, behavior and development in tank culture. Aquaculture, 997, v. 159, n. 1, p. 19-32.

[70] O. Postolache, P. Girao, M. Pereira, H. Ramos, An IR turbidity sensor: design and application [virtual instrument]. 19th IEEE Instrumentation and Measurement Technology Conference, Alaska, USA, 21-23 May, 2002, p. 535-539.

[71] T. P. Lambrou, C. C. Anastasiou, C. G. Panayiotou, A nephelometric turbidity system for monitoring residential drinking water quality. Int. Conf. on Sensor Applications, Experimentation and Logistics, Athens, Greece, 25 Sept. 2009.

[72] E. Tokhtuev, C. Owen, A. Skirda, V. Slobodyan, J. Goin, Turbidity sensor. U.S. Patent No6,842,243, 11Jan. 2005.

[73] S. Sendra, L. Parra, V. Ortuno, J. Lloret, A low cost turbidity sensor development. 7th Int. Conf. on Sensor Technologies and Applications, Barcelona, Spain, 25-31 Aug., 2013.

[74] T. R. Giuffre, B. B. Figi, S. D. Patel, T. M. Moyer, Overmolded flowthrough turbidity sensor. U.S. Patent No 5,923,433, 13 Jul. 1999. [75] J. R. Biard, Turbidity sensor with the capability of regulating the intensity of a light source. U.S. Patent No5,589,935, 31 Dec. 1996

[76] M. B. Shenoy, B. P. Pal, B. D. Gupta, Design, analysis, and realization of a turbidity sensor based on collection of scattered light by a fiber-optic probe. IEEE Sensors J., 2012, v. 12, n 1, p. 44-50.

[77] O. Postolache, J. D. Pereira, P. S. Girao, An intelligent turbidity and temperature sensing unit for water quality assessment. Canadian Conf. on Electrical and Computer Engineering, Manitoba, Canada, 12-15 of May, 2002.

[78] N. J. Clifford, K. S. Richards, R. A. Brown, S. N. Lane, Laboratory and field assessment of an infrared turbidity probe and its response to particle size and variation in suspended sediment concentration. Hydrolog Sci J, 1995, v. 40, n. 6, p. 771-791.

[79] K. Kawanisi, S. Yokosi, Characteristics of suspended sediment and turbulence in a tidal boundary layer. Cont Shelf Res, 1997, v. 17, n. 8 , p. $859-875$.

[80] G. Voulgaris, S. T. Meyers, Temporal variability of hydrodynamics, sediment concentration and sediment settling 
velocity in a tidal creek. Cont Shelf Res, 2004, v. 24, n. 15, p. 16591683.

[81] M. Trevethan, H. Chanson, M. Takeuchi, Continuous highfrequency turbulence and suspended sediment concentration measurements in an upper estuary. Estuarine, Coastal and Shelf Science, 2007, v. 73, n. 1, p. 341-350.

[82] H. Chanson, M. Takeuchi, M. Trevethan, Using turbidity and acoustic backscatter intensity as surrogate measures of suspended sediment concentration in a small subtropical estuary. J Environ Manage, 2008, v. 88 , n. 4 , p. $1406-1416$.

[83] M. I. Vousdoukas, S. Aleksiadis, C. Grenz, R. Verney, Comparisons of acoustic and optical sensors for suspended sediment concentration measurements under non-homogeneous solutions. J Coastal Res, 2011, v. 64, p. 160.

[84] H. Chanson, D. Reungoat, B. Simon, P. Lubin, High-frequency turbulence and suspended sediment concentration measurements in the Garonne River tidal bore. Estuarine, Coastal and Shelf Science, 2011, v. 95 , n. 2, p. 298-306.

[85] H. Marttila, H. Postila, B. Kløve, Calibration of turbidity meter and acoustic doppler velocimetry (Triton-ADV) for sediment types present in drained peatland headwaters: Focus on particulate organic peat. River Res Appl, 2010, v. 26, n. 8, p. 1019-1035.

[86] Aqua TROLL 600, https:// goo.gl/Jqnwew. Last access:19/09/17

[87] TROLL 9500, https:// goo.gl/2nB2NU Last access: 19/09/17

[88]MPS-K16/Qualilog16, http://goo.gl/wFTSyh.Last access:30/1/18

[89]MPS-D8/Qualilog8, http://goo.gl/8mmYRC. Last access: 30/1/18

[90] HI9829, http:// goo.gl/4xpEDL. Last access: 19/09/17

[91] R. A. Locarnini, A. V. Mishonov, J. I. Antonov, T. P. Boyer, H. E. Garcia, O. K. Baranova, M. M. Zweng, D. R. Johnson World Ocean Atlas 2009, Volume 1: Temperature. S. Levitus, Ed., NOAA Atlas NESDIS 68, U.S. Government Printing Office, Washington, D.C., 2010.

[92] J. I. Antonov, D. Seidov, T. P. Boyer, R. A. Locarnini, A. V. Mishonov, H. E. Garcia, O. K. Baranova, M. M. Zweng, D. R. Johnson, World Ocean Atlas Volume 2: Salinity. S. Levitus Ed. NOAA Atlas NESDIS 69, U.S. Gov. Printing Office, Washington, D.C., 2009, p. 184.

[93] H. E. Garcia, R. A. Locarnin, T. P. Boyer, J. I. Antonov, O. K. Baranova, M. M. Zweng, D. R. Johnson, World Ocean Atlas 2009 Volume 3: Dissolved Oxygen, Apparent Oxygen Utilization, and Oxygen Saturation. S. Levitus, Ed., NOAA Atlas NESDIS 70, U.S. Government Printing Office, Washington, D.C., 2010, p. 344.

[94] C. Encinas, E. Ruiz, J. Cortez, A. Espinoza, Design and implementation of a distributed IoT system for the monitoring of water quality in aquaculture. Int. Conf. on IEEE Wireless Telecommunications Symposium (WTS), Chicago, USA, Apr. 26-28, 2017.

[95] J. Rocher, L. Parra, M. Taha, J. Lloret, Diseño de una red de sensores para monitorizar una instalación acuícola. Int. Conf. on XIII Jornadas de Ingeniería Telemática (JITEL 2017), Valencia, Spain, Sept. 27-29, 2017. 